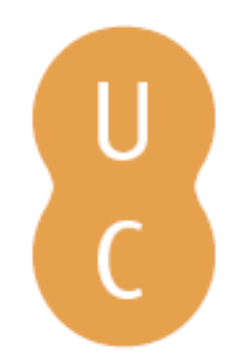

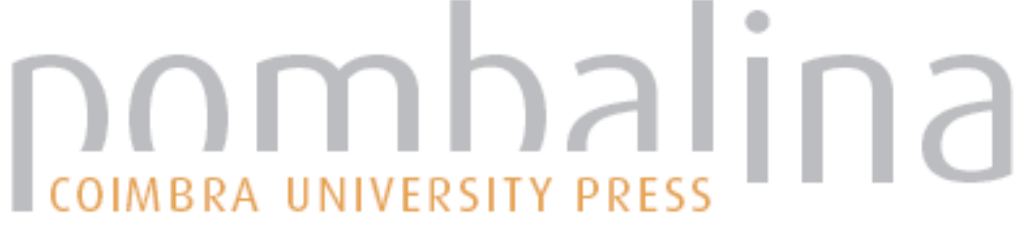

\section{Arte nacional: conceito e funcionalidade}

Autor(es): Rosmaninho, Nuno

Publicado por: Imprensa da Universidade de Coimbra

URL

persistente: $\quad$ URI:http://hdl.handle.net/10316.2/31644

DOI: $\quad$ DOI:http://dx.doi.org/10.14195/978-989-26-0199-1_34

Accessed : $\quad$ 26-Apr-2023 10:56:47

A navegação consulta e descarregamento dos títulos inseridos nas Bibliotecas Digitais UC Digitalis, UC Pombalina e UC Impactum, pressupõem a aceitação plena e sem reservas dos Termos e Condições de Uso destas Bibliotecas Digitais, disponíveis em https://digitalis.uc.pt/pt-pt/termos.

Conforme exposto nos referidos Termos e Condições de Uso, o descarregamento de títulos de acesso restrito requer uma licença válida de autorização devendo o utilizador aceder ao(s) documento(s) a partir de um endereço de IP da instituição detentora da supramencionada licença.

Ao utilizador é apenas permitido o descarregamento para uso pessoal, pelo que o emprego do(s) título(s) descarregado(s) para outro fim, designadamente comercial, carece de autorização do respetivo autor ou editor da obra.

Na medida em que todas as obras da UC Digitalis se encontram protegidas pelo Código do Direito de Autor e Direitos Conexos e demais legislação aplicável, toda a cópia, parcial ou total, deste documento, nos casos em que é legalmente admitida, deverá conter ou fazer-se acompanhar por este aviso.

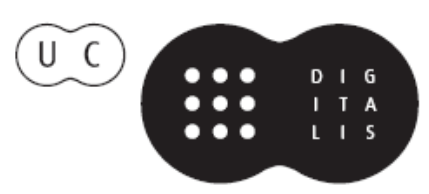


Maria Manuela Tavares Ribeiro

Coordenação

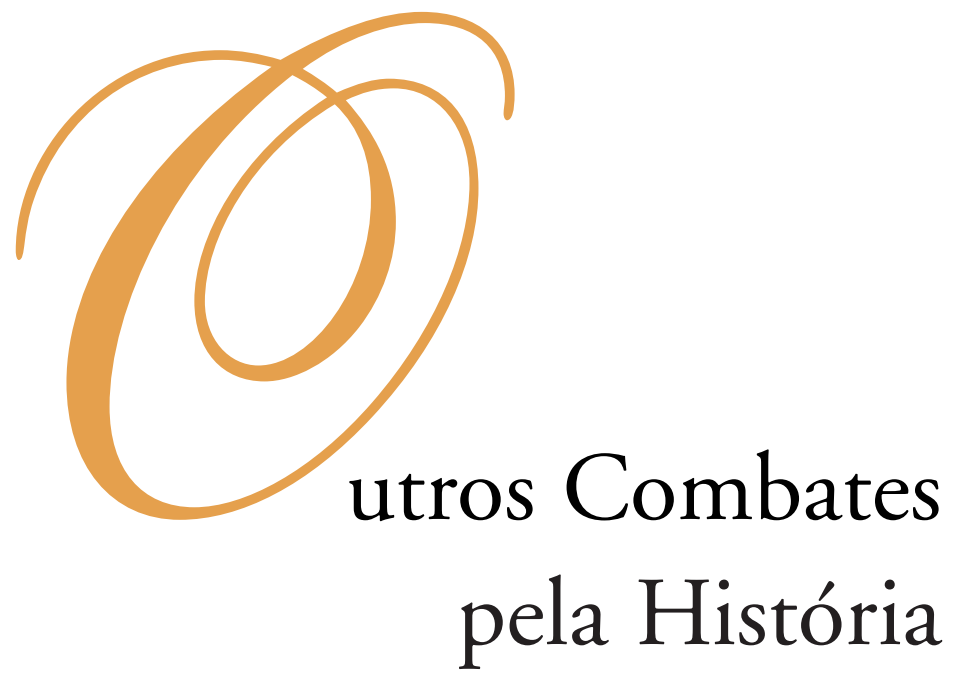




\section{COORDENAÇĀO EDITORIAL}

Imprensa da Universidade de Coimbra

Email: imprensauc@ci.uc.pt

URL: http://www.uc.pt/imprensa_uc

Vendas online: http://livrariadaimprensa.com

\section{CONCEPÇÃO GRÁFICA}

António Barros

\section{ORgANIZAÇĀO DOS TEXTOS}

Isabel Maria Luciano

Marlene Taveira

PRÉ-IMPRESSÃO

António Resende

Imprensa da Universidade de Coimbra

EXECUÇÃO GRÁFICA

SerSilito • Maia

ISBN

978-989-26-0041-3

DEPósito LEGAL

OBRA PUBLICADA COM O APOIO DE:

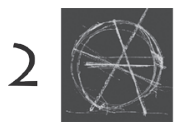

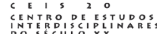

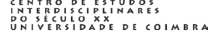

FCT Fundação para a Ciência e a Tecnologia

MINISTÉRIO DA CIÊNCIA, TECNOLOGIA E ENSINO SUPERIOR Portugal

Programa Operacional Ciência, Tecnologia, INOVAÇĀo DO QUADRo COMUNITÁRIO DE APOIO III

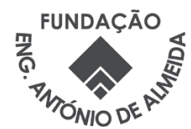

C JULHO 2010, IMPRENSA DA UNIVERSIDADE DE COIMBRA 
Maria Manuela Tavares Ribeiro

Coordenação

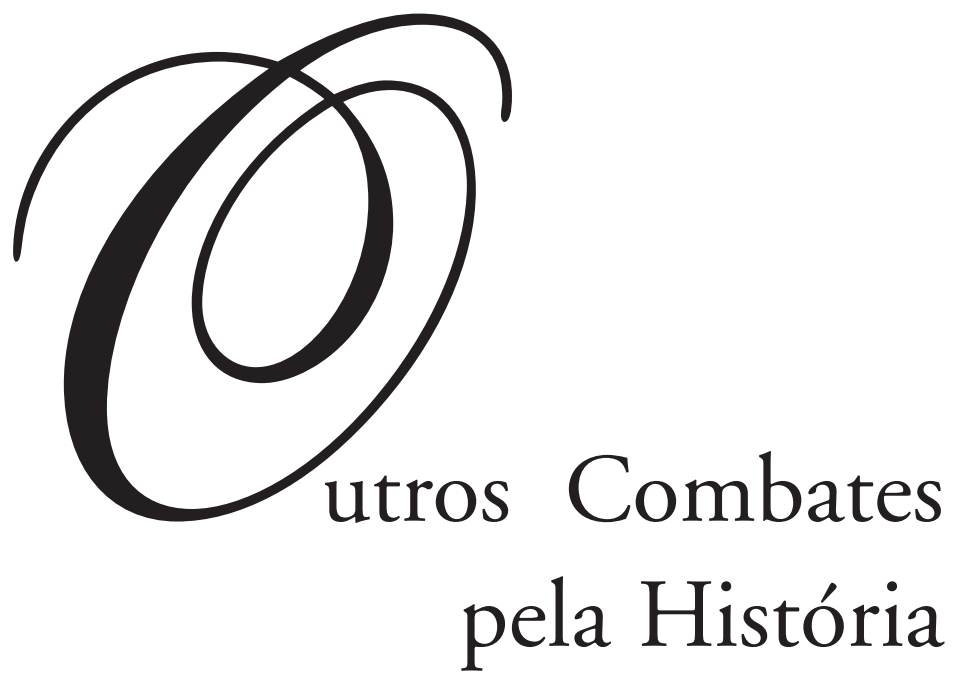

- colmbra 2010 
História, Ideias e Artes 


\section{Nuno Rosmaninho}

\section{ARTE NACIONAL: CONCEITO E FUNCIONALIDADE}

\section{Nação: descoberta e reinvenção}

A nação é uma identidade colectiva que apela a um discurso sobre a unidade, a originalidade e a diferença. Independentemente de se reportar à «vontade geral» ou ao sentimento de pertença a um povo (com a sua língua, raça, história e cultura), apresenta-se como uma comunidade imaginada (Benedict Anderson). A identidade nacional é um fenómeno mental, aprendido, que não depende automaticamente de factores geográficos, étnicos ou religiosos, mas apenas da vontade colectiva de viver em comum. Anne-Marie Thiesse dá uma forma extrema a esta ideia: "A nação nasce de um postulado e de uma invenção. Mas só se mantém viva com a adesão colectiva a essa ficção.» ${ }^{1}$

As diferentes histórias nacionais contêm um traço comum da maior importância: a denodada procura e reinvenção de uma cultura própria. A criação das culturas nacionais constitui uma corrente internacional recente, que assenta, de modo paradoxal, na invenção de mitos da sua antiguidade. Nasce num pequeno grupo de pessoas cultas, mas propaga-se com rapidez, até se tornar, em poucas décadas, num movimento de massas. A partir de meados do século XVIII, a identidade nacional afirmou-se como um princípio criador original, ao estabelecer uma nova teoria da cultura, que tende a substituir, como referência, a Antiguidade greco-romana pelas épocas bárbaras das origens remotas da nação. A nação está no Povo, «fóssil vivo» desses primeiros antepassados. É ao Povo e à sua cultura que se torna necessário «regressar» para encontrar os fundamentos da Nação.

Como facilmente se compreende, a reinvenção das culturas nacionais relaciona-se intimamente com a descoberta dos próprios países: descoberta da história, dos heróis, do Povo e da própria paisagem. Se o patriotismo não é senão o "amor das nossas coisas", principalmente, como é natural, daquelas que melhor nos identificam, distinguem e exaltam, tal afeição supõe um conhecimento razoável do País, que no princípio do século XIX manifestamente não existia. Nem a História, nem a Literatura,

\footnotetext{
${ }^{1}$ Anne-Marie Thiesse, A Criação das Identidades Nacionais. Lisboa, Temas e Debates, 2000, p. 18.
} 
nem a Antropologia, nem os estudos artísticos e patrimoniais ofereciam nessa data uma visão global de Portugal.

A verdadeira descoberta de Portugal realizou-se nas décadas seguintes. Não nos referimos apenas à descoberta do património, mas à da realidade geográfica e paisagística, entusiasticamente sugerida por Almeida Garrett nas Viagens na Minha Terra e, em 1843, num artigo do Jornal de Belas-Artes: sair das cidades, abandonar a política, tomar um vapor, subir o Tejo até Vila Nova, embarcar num batel e admirar, por fim, as «águas saborosas, margens risonhas, paragens ilustradas por acçôes generosas, — um panorama delicioso, uma continuada mutação de cenas lindíssimas!»

O conhecimento do País não resulta apenas da soma de novas informações. Teve uma dimensão ideológica fundamental, que procurarei agora aplicar à arte.

\section{Feição estereotípica}

Arte nacional começou por exprimir mais uma ambição do que um território. A sua ideia ganhou espaço a partir de 1840, tornou-se uma preocupação maior no final do século XIX e um desígnio obsidiante durante o Estado Novo.

O tema insinuou-se a partir de dois tópicos: o estilo manuelino e a pintura dos séculos XV e XVI. Nos anos em que estas propostas nasceram para um debate que se havia de prolongar durante mais de um século, já o Jornal de Belas-Artes clamava pelo «regresso» ao Povo, dando os mais vigorosos exemplos literários e elogiando as aproximações de Roquemont à pintura de costumes.

A arte nacional conheceu um movimento pendular: procura de especificidades no passado, criação ideologicamente orientada no presente. À primeira vista, parecia suficiente encontrar um estilo nacional. A sofisticação da pesquisa acabou por consagrar invariantes estilísticas ou espirituais, vagas, inverificáveis, mas de grande ressonância e força mobilizadora.

Apesar da falta de discussão teórica dos conceitos, é evidente a tendência para conceber a arte como uma expressão da autonomia espiritual da nação. Ramalho Ortigão e José de Figueiredo radicaram a originalidade artística nas mesmas particularidades históricas, culturais, étnicas e mesológicas que fundamentam a independência nacional. E neste caso, a arte nacional constitui uma aporia, uma necessidade e, como os regimes autoritários e totalitários vincarão, um dever.

Um dos aspectos mais relevantes da arte nacional é o seu carácter estereotípico. Os pintores e arquitectos ouviram constantes apelos ao aportuguesamento, mas poucas indicações precisas acerca dos procedimentos

A feição estereotípica alcançou uma das máximas expressões no fenómeno da casa portuguesa. O estudo comparado das casas rústicas, criadas por toda a Europa nas últimas décadas do século XIX, mostra o potencial hermenêutico do enfoque nacional. Divididos pela ideologia, os defensores e os adversários da casa portuguesa discutiram sem se ouvirem. O regionalismo arquitectónico não configura apenas uma reacção à industrialização ou uma apologia do regresso ao campo. Demonstra a capacidade de o mundo rural sustentar uma cultura nacional.

A emergência de casas nacionais em países tão distintos como França, Hungria, Polónia, Finlândia, Suécia, Rússia, Roménia e EUA evidencia a necessidade de integrar 
a casa portuguesa num contexto internacional e, em vez de perseguir uma mirífica base etnográfica, compreender que se está perante uma reinvenção, aliás nunca negada por Raul Lino. Surgida como hipótese no final do século XIX e relegada pela dúvida etnográfica durante mais de uma década, foi por fim criada pelos arquitectos e pelas revistas da especialidade a partir sobretudo da segunda década do século XX, quando Rocha Peixoto já havia demonstrado a sua inconsistência tradicional.

A confusão com a arquitectura popular constitui, aliás, um dos mais persistentes equívocos. A casa portuguesa é um eclectismo pseudo-vernáculo e, como todos os eclectismos, privilegia o decorativismo. A sua longevidade tem uma expressão artística irrecusável, mas restaria incompreensível se não se observasse o seu fundamento nacional. A confusão com a arquitectura do povo manteve-se apesar da pronta resposta dos etnólogos e do estudo exaustivo do Sindicato dos Arquitectos nos anos cinquenta. $\mathrm{O}$ mito resistiu às verdades conhecidas porque é a expressão do ideário neogarrettiano e de um entendimento ecléctico da arquitectura e porque se converteu num dos mais persistentes abrigos da retórica da tradição, consagrada pelo movimento das nacionalidades.

\section{Neogarrettismo}

Neogarrettismo é o termo que melhor designa o encontro entre a literatura, a pintura e a própria fotografia na transição para o século XX. Ainda antes de Silva Porto pintar as suas cenas rurais e de Alberto de Oliveira invocar o nome de Garrett, Júlio Dinis criou um universo neogarrettiano avant la lettre. Os seus quatro romances revelam uma preferência pelos ambientes rústicos, apesar de só os conhecer de estadas curativas. O que ressalta nos seus livros, «romances de costumes que têm a aparência ou a solução de romances de amor», na perspicaz observação de José-Augusto França, é «a doçura duma vida patriarcal em que a Natureza se apresenta como garantia da honestidade dos caracteres» ${ }^{2}$.

Júlio Dinis marca um caminho, que nos anos de 1891 a 1894 se alargou com os contos de Os Meus Amores, de Trindade Coelho, os poemas de Os Simples, de Guerra Junqueiro, as crónicas de Palavras Loucas, de Alberto de Oliveira, e a emergência da questão da casa portuguesa, modos convergentes de expressão de uma pax rustica. ${ }^{3}$

Em nenhum pintor essa pax rustica foi tão exuberantemente exposta e geralmente reconhecida como em José Malhoa. Não nos referimos, como é evidente, à pintura de história, que ocupa um lugar secundário na sua obra, nem às representaçôes da burguesia urbana, raras, ou das paisagens, mais frequentes no início da carreira. O José Malhoa consagrado pela opinião ilustrada do tempo é o que pinta o povo, sobretudo o povo rural. A despeito de outras qualidades, foi a capacidade de recriar o universo campestre, segundo uma visão neogarrettiana, que atraiu as atenções e fidelizou os seus admiradores.

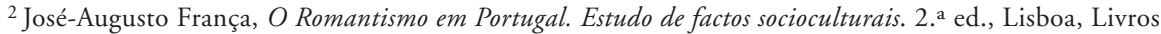
Horizonte, 1993, p. 426.

${ }^{3}$ Expressão usada por José-Augusto França, O Romantismo em Portugal, p. 554.
} 
O mundo rural esteve na origem do alegado portuguesismo, um dos tópicos mais consensuais criados em torno de José Malhoa. A ideia de que seria «o pintor mais português de Portugal» acentuou-se particularmente na década de 1890. Valorizou-se até ao exagero o facto de não ter sido pensionista no estrangeiro, como se isso o tivesse afastado de influências nefastas e garantido a expressão de um "puro portuguesismo", do "génio da raça». ${ }^{4}$ A Comédia de 2 de Junho de 1902 considerou-o o "mais nacional de todos os pintores portugueses, aquele que menos se deixou influir pelas imitaçóes do estrangeiro, e que melhor interpreta o sentimento da nossa boa terra cantante e luminosa». E quase cinquenta anos decorridos, Egas Moniz escreveu que a sua "pintura é Portugal».

"As imagens contaminam», assinala António Sena, referindo-se à mútua influência da pintura e da fotografia. "As semelhanças «artísticas» entre as fotografias de Marques Abreu ou Alvão e a pintura de José Malhoa (1855-1933) — desde "Cócegas» (1904), passando por «Só na Aldeia» (1911), até "Paleio» (1930) — não são apenas temáticas. São afinidades mais profundas que permitem supor alguma admiração e atenção recíprocas. $\aleph^{5}$ É esta sintonia das artes que pretendemos destacar. O gosto naturalista e pictorialista criou em fotografia, como José Malhoa realizou na pintura, uma identidade portuguesa recortada nas paisagens, nas gentes e nos costumes essencialmente rurais.

\section{Temas e essências}

No desenvolvimento da arte nacional, tal como no dos próprios ideários, a última década de Oitocentos marca uma viragem. A revista Arte Portuguesa, publicada durante o ano de 1895, evidencia uma tendência para passar da pesquisa histórica de uma "estética portuguesa» para a sua aplicação prática. Pela força que assumem, os modos de nacionalização da arte são o elemento verdadeiramente inovador deste periódico e da sua época.

Os temas foram o principal modo de nacionalização da arte durante os séculos XIX e XX, em parte porque eram uma via directa de acesso à cultura popular: melodias populares, na música; vivências campestres, na pintura; a casa portuguesa, na arquitectura. Os discursos sobre a identidade artística portuguesa assumiam um carácter hipotético ou conjectural e exerciam-se no âmbito concreto de autorias, estilos e particularidades decorativas.

$\mathrm{Na}$ transição para o século XX, a procura de uma arte nacional refinou os seus processos. Reconheceu-se que a simplicidade de um estilo arquitectónico não satisfazia o objectivo de encontrar uma autonomia espiritual estruturada, aplicável a todos os campos da cultura e a todos os momentos históricos. As convicçôes nacionalistas passaram a tolerar menos a dúvida e o carácter transitório das especificidades, acabando por impor discursos assertivos e interpretaçóes essencialistas.

\footnotetext{
${ }^{4}$ Paulo Henriques, José Malhoa. Lisboa, Círculo de Leitores, 1997, p. 164.

${ }^{5}$ António Sena, História da Imagem Fotográfica em Portugal (1839-1997). Porto, Porto Editora, 1998, pp. 216 e 217.
} 
A leitura essencialista da identidade artística portuguesa emergiu da busca de uma "escola portuguesa de pintura», ao tomar traços caracterológicos que a aproximam de outros ramos da cultura. Enquanto se recriava o tópico da saudade, José de Figueiredo inaugurava o estudo dos painéis de Nuno Gonçalves afirmando, em 1910, que «a arte portuguesa, conformemente ao temperamento da nossa raça, é uma arte calma, docemente contemplativa» ${ }^{6}$. Daqui decorreu a ideia de um sentimento estético português, que Reynaldo dos Santos perseguiu com vigor até 1970.

Este foi, aliás, um dos autores que melhor correspondeu às novas tendências, colocando a sua reputação científica ao serviço de um desiderato intrinsecamente nacionalista. A ele se devem as sínteses acerca das "constantes de sensibilidade artística portuguesa", de validade trans-histórica, expostas em artigos intitulados $O$ Espirito e a Essência da Arte em Portugal (1941) e o Carácter da Arte Portuguesa Através dos Tempos (1961).

Reynaldo dos Santos aplicou à arte o «nacionalismo científico» defendido pelo antropólogo Mendes Correia. Tratava-se de engrandecer a pátria através dos estudos artísticos, revelando a personalidade da nação. É também em termos caracterológicos que o portuguesismo é definido por Luís de Freitas Branco e Santiago Kastner na música (lirismo, idealismo e simpatia, para o primeiro; ternura, saudade, grande humanidade e simplicidade, para o segundo), por Jorge Dias na antropologia cultural (simpatia, espírito sonhador e imaginativo, embora com sentido prático, capacidade de adaptação e ausência de sentimento rácico), por Jaime Cortesão na história (hombridade, plasticidade amorável e inquietação) e por Joaquim de Carvalho na cultura (constância multissecular, substrato afectivo e tendência saudosista). ${ }^{7}$

A procura das essências conduziu a identidade nacional a um plano conceptual tão etéreo que se tornou possível unir, num único discurso, convicções artísticas, ideológicas e políticas. Serve de exemplo o ensaio de Eduardo Malta sobre Nuno Gonçalves, considerado um pintor original, insofismavelmente português, verdadeiro "pintor-modelo de uma raça» ${ }^{8}$. Nuno Gonçalves apresenta-se, em 1932, como o che$f e$, o unificador da pintura portuguesa, o guia de todos os pintores, aquele que acabaria com os percursos transviados e mostraria a verdade na arte, que então se procurava também na política.

A defesa intransigente de uma identidade artística nacional conduziu a tentativas de imposição de normas estéticas. Até ao fim do século XIX, as indicações revestem-se de um carácter benigno. Adquirem um arroubo exclusivista durante o neogarrettismo. E chegam a constituir uma obrigação do Estado nos regimes autoritários e totalitários.

\footnotetext{
${ }^{6}$ José de Figueiredo, O Pintor Nuno Gonçalves. Lisboa, 1910, pp. 134-135.

${ }^{7}$ Jorge Dias, Os Elementos Fundamentais da Cultura Portuguesa. Lisboa, Imprensa Nacional-Casa da Moeda, 1985, conferência originalmente proferida em 1950; Joaquim de Carvalho, Compleição do Patriotismo Português. Coimbra, Atlântida, 1953; Jaime Cortesão, O Humanismo Universalista dos Portugueses. Lisboa, Portugália Editora, s.d.; Teresa Cascudo, «Razão vs. Quimera na musicologia portuguesa da primeira metade do século XX», in: António Pedro Pita e Luís Trindade (coord.), Transformaçōes Estruturais do Campo Cultural Português (1900-1950). Coimbra, Ariadne Editora/CEIS20, 2005, sobretudo pp. 408 e ss.

${ }^{8}$ Eduardo Malta, Nuno Gonçalves. S.1., s.e., 1932, pp. 13-15 e 21.
} 
O que antes era um movimento liderado pelos intelectuais passou gradualmente a ser assumido pelos políticos. As propostas converteram-se em exigências. A arte nacional oficializou-se. Raul Lino e o pintor Severo Portela Júnior pediram ao Estado que controlasse a actividade artística.

\section{Antimodernismo}

É no enfoque nacional oitocentista que se encontram as raízes mais profundas do antimodernismo desenvolvido nos regimes totalitários. A animosidade contra o estrangeiro, observada em algumas passagens de Almeida Garrett, apresenta uma cordialidade que as primeiras décadas do século XX substituirão por um tom cada vez mais irascível. O antimodernismo tem várias motivações. Uma das mais importantes é precisamente o seu internacionalismo. Em Portugal, entre os anos vinte e sessenta, a arte moderna foi atacada em nome da beleza, da moral, da raça, da civilização ocidental, do cristianismo e da própria nação. Mas foi nas décadas de trinta e quarenta que a lógica nacional conduziu à tentativa de estatização do antimodernismo, patente em escritos de Raul Lino, Fernando de Pamplona e de António Ferro.

Creio poder falar-se de um antimodernismo nacionalista, no qual os aspectos políticos sobrelevam as considerações estéticas. A alegada consagração da arte moderna, realizada por António Ferro e pelo SPN/SNI, não é mais do que a estatização parcial do antimodernismo. A tendência para recusar a arte moderna, patente em máximo grau no nazismo e no estalinismo, assumiu no Estado Novo uma feição menos radical nas suas consequências. Se a análise estética deste processo ainda levanta dúvidas, a dimensão ideológica é indiscutível. Basta ler a obra integral de António Ferro para concluir que abandonou o modernismo quando adoptou o nacionalismo. E que foi como nacionalista que, à frente do SPN/SNI, procedeu à domesticação da arte moderna. Dele se pode dizer, portanto, que foi modernista contra a nação e nacionalista contra o modernismo. ${ }^{9}$

\section{Contra a arte nacional}

A arte nacional é uma corrente que nasce amigavelmente nos anos de 1840 , cresce no meio século seguinte e torna-se caudalosa, exclusivista, arrastando artistas, intelectuais e políticos. Chegou a parecer unânime. Mas, em cada época houve autores isolados, por vezes quase silenciosos, que se ergueram contra o "preconceito nacionalista». Já lhe chamei «uma ilustre linhagem»: Athanasius Raczynski, que diminuiu a importância desse enfoque; Joaquim de Vasconcelos, que atacou a fixação nacionalista no estilo manuelino e preveniu contra a «ignorância vaidosa para maior glória da Pátria» ${ }^{10}$;

\footnotetext{
${ }^{9}$ Foi precisamente o que escrevemos e tentámos provar no artigo «António Ferro e a propaganda nacional antimoderna», in: Luís Reis Torgal e Heloísa Paulo (coord.), Estados Autoritários e Totalitários e Suas Representaçôes. Coimbra, Imprensa da Universidade, 2008, pp. 289-299.

${ }^{10}$ Joaquim de Vasconcelos, A Pintura Portuguesa nos Séculos XV e XVI. Porto, 1881, pp. 9 e 35.
} 
Vergílio Correia e António Nogueira Gonçalves, que ostensivamente a ignoraram; Fernando Lopes-Graça, que no início dos anos trinta realizou o primeiro grande ataque ao portuguesismo estereotipado, ele que haveria de cultivar intensamente a fonte popular; os jovens arquitectos do congresso de 1948, que precisavam de se libertar de um peso que os constrangia.

Foi sempre fácil mostrar a inconsistência da arte nacional. O que parece ter faltado foi a vontade. Em 1945, a expressão estética do edifício da Faculdade de Letras da Universidade de Coimbra motivou uma troca de argumentos entre Cottinelli Telmo e o Conselho Superior de Obras Públicas que revelou a vacuidade em que caíra a militância nacionalista em arte. O relator do parecer daquele organismo, Rodrigues de Carvalho, defendia a necessidade de harmonizar o imóvel «com o ambiente e as tradiçôes locais» de Coimbra e do próprio País. No entanto, convidado a ser mais explícito, não foi capaz de sair do lugar-comum, deixando ao arquitecto a tarefa de encontrar uma «ideia bem nossa». Um século de argumentação nacional não conseguiu ultrapassar os pontos fracos de um discurso estereotípico. Os argumentos eram menos importantes do que a motivação.

Por trás do emaranhado de caminhos, a arte nacional apresenta móbiles estáveis, sintetizados por Anders Aman para a arquitectura. ${ }^{11}$ Tratou-se sempre de renovar através da tradição. É neste discurso paradoxal que reside uma das mais importantes chaves hermenêuticas do nacionalismo artístico.

${ }^{11}$ Anders Aman, Architecture and Ideology in Eastern Europe During the Stalin Era. An aspect of cold war history. Nova Iorque e outras, The Architectural History Foundation / The MIT Press, 1992. (Título da edição original: Arkitektur och Ideologi in Stalintidens Östeuropa. Ur det kalla krigets historia, 1987). 
Série

Documentos

Imprensa da Universidade de Coimbra

Coimbra University Press

2010

- U

C • 